\title{
TURISMO SUSTENTÁVEL E MEIOS DE HOSPEDAGEM: UMA AVALIAÇÃO DA SUSTENTABILIDADE HOTELEIRA EM BARRA GRANDE, MARAÚ (BA)
}

SUSTAINABLE TOURISM AND LODGING FACILITIES: AN EVALUATION OF THE HOTEL SUSTAINABILITY IN BARRA GRANDE, MARAU (BA)

TURISMO SOSTENIBLE Y MEDIOS DE HOSPEDAJE: UNA VALORACIÓN DE LA SOSTENIBILIDAD HOTELERA EN BARRA GRANDE, MARAÚ (BA)

\section{Carlos Henrique Leite Borges}

Professor do Dep. de Ciências Econômicas da Universidade Estadual de Santa Cruz (UESC) chlborges@uesc.br

\section{Marcelo Inácio Ferreira Ferraz}

Professor do Dep. de Ciências Exatas da Universidade Estadual de Santa Cruz (UESC) mfferraz@uesc.br

\section{Adriana Vilas-Boas Borges}

Tutora de sala Unopar - polo Itabuna (BA) adrianaguerrieri@hotmail.com

Data de Submissão: 27/02/2015 Data de Aprovação: 02/07/2015

Resumo: Este trabalho objetivou avaliar as condições dos meios de hospedagem sob as quais se desenvolvem as práticas para o turismo sustentável na vila de Barra Grande em Maraú (BA). Considerando que o turismo mobiliza toda a comunidade na busca de benefícios socioeconômicos, 
torna-se relevante conhecer a contribuição do setor hoteleiro para o desenvolvimento sustentável da atividade por meio do índice de sustentabilidade hoteleira. Os procedimentos metodológicos tiveram caráter descritivo e exploratório e foi utilizado como procedimento o levantamento do tipo survey, levando-se em conta indicadores baseados no funcionamento do estabelecimento e no comportamento de visitantes e funcionários. Os resultados revelaram um índice de sustentabilidade hoteleira com valor de 0,39, representando uma condição insatisfatória e sugerindo que a adoção de práticas sustentáveis por parte dos meios de hospedagem ainda são incipientes. Depreendese, portanto, que muito ainda há de ser feito para que os meios de hospedagem contribuam significativamente para o turismo sustentável nessa localidade.

Palavras-chave: Turismo Sustentável. Indicadores. Índice de Sustentabilidade.

Abstract: This study evaluates the conditions of lodging facilities under which practices for sustainable tourism in the village of Barra Grande in Marau (BA) are developed. Seeing that tourism mobilizes the entire community in the pursuit of socio-economic benefits, it is crucial to know the contribution of the hotel sector for the sustainable development of the activity through the hotel sustainability index. The methodological procedures were descriptive and exploratory, and the survey procedure was used, taking into account indicators based on the operation of the establishment and the behavior of visitors and employees. The results revealed a hotel sustainability index with a value of 0.39 , representing an unsatisfactory condition and suggesting that the adoption of sustainable practices by lodging facilities are still incipient. It appears, therefore, that much remains to be done if lodging facilities are to contribute significantly to sustainable tourism in the region studied.

Keywords: Sustainable Tourism. Indicators. Sustainability Index.

Resumen: Este trabajo se propuso evaluar las condiciones de los medios de hospedaje bajo las que se desarrollan las prácticas para el turismo sostenible en la villa de Barra Grande, en Maraú (BA). Considerando que el turismo mueve a toda la comunidad en la búsqueda de beneficios socioeconómicos, se hace relevante conocer la contribución del sector hotelero para el desarrollo sostenible de la actividad por medio del índice de sostenibilidad hotelera. Los procedimientos metodológicos tuvieron carácter descriptivo y exploratorio y como procedimiento se utilizó una encuesta de tipo survey, tomando en cuenta indicadores basados en el funcionamiento del establecimiento y en el comportamiento de visitantes y empleados. Los resultados revelaron un índice de sostenibilidad hotelera con valor de 0,39, representando una condición insatisfactoria y sugiriendo que la adopción de prácticas sostenibles por parte de los medios de hospedaje es aún incipiente. Se desprende, por lo tanto, que todavía hay que hacer mucho para que los medios de hospedaje contribuyan significativamente con el turismo sostenible en esa localidad.

Palabras clave: Turismo Sostenible. Indicadores. Índice de Sostenibilidad.

INTRODUÇÃO 
(CNUMAD), realizada no Rio de Janeiro em 1992. A "Agenda 21 para a Indústria de Viagens e Turismo para o Desenvolvimento Sustentável" (OMT, 1994) surgiu como um desdobramento dessa proposta e indicou áreas prioritárias para o desenvolvimento de programas e procedimentos para a implementação do turismo sustentável. Os princípios de sustentabilidade passaram a permear a conduta de todos os agentes envolvidos com o desenvolvimento do turismo de forma que seus impactos fossem os menores possíveis.

Do setor hoteleiro, parte ativa neste processo, é exigida cada vez mais a incorporação de práticas voltadas para a minimização dos impactos sobre os recursos naturais. Apesar de a indústria turística preocupar-se excessivamente em lucros extraordinários e com ações de sustentabilidade incipientes e isoladas, determinadas principalmente por leis ou por redução de custos, alguns hotéis já começam a introduzir em suas operações procedimentos que buscam reduzir seus impactos socioambientais (SWARBROOKE, 2000; BUCKLEY, 2012; MALTA; MARIANI, 2013).

De acordo com Butler (2008), grandes redes hoteleiras, como Marriott, Hilton, Fairmont e Starwood, desenvolveram iniciativas e programas ambientais na tentativa de mitigar os impactos resultantes de suas operações. Outras iniciativas aparecem no mundo e no Brasil, ainda que de forma embrionária, com foco especialmente na redução de custos e desperdícios, porém, de algum modo pode significar menor pressão sobre a exploração dos recursos (RICCI, 2002; FREITAS; ALMEIDA, 2010; VIRGINIO; FERNANDES, 2011; PERES JR.; REZENDE, 2011; MELLO et al., 2012).

Os desafios são maiores quando se trata de meios de hospedagem de pequeno porte, especialmente pousadas localizadas em pequenas comunidades costeiras de forte apelo para o turismo de sol e praia, pois sofrem substancialmente com os efeitos da alta sazonalidade, ou seja, elevado fluxo de visitantes na alta estação e pouca ou quase nenhuma movimentação no resto do ano. Os empresários do setor hoteleiro e do trade turístico concentram todos os esforços na alta estação como forma de garantir a sua sustentação econômica nos meses de fraca movimentação.

Em um momento em que a procura por formas alternativas e sustentáveis de uso do capital natural representa a própria busca por um futuro harmônico na relação homem-natureza, esta pesquisa objetivou avaliar as condições sob as 
quais se desenvolve o turismo no povoado de Barra Grande em Maraú (BA), em especial e particularmente investigando a existência de ações e procedimentos que tornem as operações dos meios de hospedagem menos impactantes ao meio ambiente e voltadas para contribuir com a sustentabilidade em suas dimensões ambiental, econômica e social.

O município de Maraú é um dos 65 destinos indutores do desenvolvimento turístico regional no Brasil, tendo a Vila de Barra Grande como o principal destino da península de Maraú e tendo o turismo como sua principal atividade econômica. Revela-se como um dos mais visitados na alta estação no litoral sul da Bahia, com seu fluxo aumentando a cada ano e já sendo visível a necessidade premente de prepará-lo para o turismo de forma competitiva e ao mesmo tempo adequada às características locais.

O desafio em tempos atuais e vindouros para destinos costeiros de pequeno porte, como povoados e vilas litorâneas, assim como é Barra Grande, é encontrar uma forma de minimizar os efeitos da pressão antrópica causada na alta estação, quando o fluxo turístico é intenso e compromete a capacidade de suporte social e ambiental do destino, ainda mais quando o lugar não dispõe de infraestrutura básica adequada ao aumento excessivo de visitantes, o que implica repercussões significativas no funcionamento do setor hoteleiro.

\section{O TURISMO NO CONTEXTO DO DESENVOLVIMENTO} SUSTENTÁVEL

No ano de 1972 um acontecimento marcou decisivamente a história do movimento ambientalista: a Conferência das Nações Unidas sobre Meio Ambiente Humano (CNUMAH), realizada em Estocolmo (Suécia). O evento tornou-se o marco do ambientalismo contemporâneo. Ao compreender a necessidade de mudar a visão dos recursos naturais como infinitos, a Organização das Nações Unidas (ONU) instituiu, em 1984, a Comissão Mundial sobre Meio Ambiente e Desenvolvimento, sob coordenação da então Primeira-Ministra norueguesa Gro Harlem Brundtland. Em 1987, o comitê apresentou o relatório final intitulado "Nosso Futuro Comum" (Our Common Future) (SACHS, 2002; KÖRÖSSY, 2008; HANAI, 2009). 
Naquele documento ficou consagrada, em nível internacional, a definição de desenvolvimento sustentável como sendo aquele que atende às necessidades do presente, sem comprometer a capacidade das gerações futuras atenderem também às suas. Sua emergência resulta, principalmente, da constatação de que era preciso uma via alternativa como resposta a um modelo civilizacional caracterizado por ser ecologicamente predatório, socialmente perverso e politicamente injusto (PLATIAU et al., 2005; CORDEIRO et al., 2011).

De acordo com Irving et al. (2005), a "Agenda 21 Global", aprovada durante a Conferência das Nações Unidas sobre Meio Ambiente e Desenvolvimento (CNUMAD), realizada no Rio de Janeiro em 1992, constituiu uma das referências mais importantes para a construção de novos modelos de desenvolvimento apoiados na noção de sustentabilidade.

A Agenda 21, para a Indústria de Viagens e Turismo para o Desenvolvimento Sustentável (OMT, 1994), surgiu como um desdobramento dessa proposta e direcionou as ações para o desenvolvimento de programas e procedimentos para o turismo sustentável.

Desta forma, sobre o turismo no âmbito da Sustentabilidade a OMT, com base no informe Brundtland, define o desenvolvimento turístico sustentável como aquele que:

...atende às necessidades dos turistas atuais e das regiões receptoras e ao mesmo tempo protege e fomenta as oportunidades para o turismo futuro. Concebe-se como um caminho para a gestão de todos os recursos de forma que possam satisfazer as necessidades econômicas, sociais e estéticas, respeitando ao mesmo tempo a integridade cultural, os processos ecológicos essenciais, a diversidade biológica e os sistemas que sustentam a vida. (OMT citado por DIAS, 2003).

A ideia de turismo sustentável, segundo Körössy (2008), sedimentouse em 1995 nas Ilhas Canárias (Lanzarote, Espanha), quando foi celebrada a Conferência Mundial de Turismo Sustentável, durante a qual foi elaborada a Carta do Turismo Sustentável (Charter for Sustainable Tourism). Entre outras coisas, o documento chamava a atenção para o fato de que o desenvolvimento da atividade turística não deve ultrapassar os limites do ambiente natural; deve 
ser economicamente viável e equitativo para as comunidades locais; deverá haver a participação dos atores sociais envolvidos nos níveis local, regional, nacional e internacional; seu planejamento deve ser elaborado por governos e autoridades competentes, contando com a participação das comunidades locais e de organizações não governamentais, de forma integrada; e deve adotar códigos de conduta e promoção de formas alternativas de turismo.

No contexto turístico, a OMT (2005) elaborou um conjunto de indicadores que avaliam as informações sobre o desenvolvimento sustentável do turismo em uma comunidade: bem-estar das comunidades receptoras; conservação do patrimônio cultural; participação comunitária no turismo; satisfação dos turistas; saúde e segurança; aproveitamento dos benefícios econômicos do turismo; proteção dos recursos naturais; gestão dos recursos naturais escassos; limitação do impacto ambiental do turismo; controle das atividades turísticas; organização e controle do lugar de destino; projeto de produtos e serviços e sustentabilidade de operações e serviços turísticos.

Em torno dessa proposta da OMT é que diversos trabalhos surgem com a preocupação em estudar o fenômeno turístico sob a perspectiva da sustentabilidade, propondo indicadores que subsidiem o planejamento da atividade em nível local. O Ministério do Turismo (2007) estabelece quatro dimensões para tratar da "sustentabilidade turística": o aspecto ambiental, o econômico, o sociocultural e o político-institucional.

A sustentabilidade ambiental compreende a interação entre a atividade turística e o meio ambiente, os impactos causados pelo turismo e sua capacidade de comprometer a qualidade e fornecimento dos serviços ambientais. Segundo Sancho (2001) citado por Barddal (2010), as principais preocupações se concentram "[...] no processo de degradação sofrido pelos recursos materiais que são utilizados no desenvolvimento das referidas atividades econômicas e no grau de irreversibilidade desse processo". Isto também se aplica ao caso da atividade turística.

O meio ambiente e o turismo estão intimamente relacionados, posto que em muitos casos o ambiente natural faz parte das atrações turísticas, exercendo fortes impactos também na vegetação, na fauna, no solo e na água. Sendo assim, 
há uma preocupação crescente em se avaliar este relacionamento (BARDDAL, 2010; RUSCHMANN, 2000; LICKORISH; JENKINS, 2000; COOPER et al., 2001; DIAS, 2003; CUNHA; CUNHA, 2005).

A sustentabilidade econômica está vinculada aos benefícios econômicos gerados pela atividade turística em decorrência do seu efeito multiplicador e sua interdependência com outros setores econômicos. O aumento ou diminuição do consumo de bens ou serviços terá reflexos não apenas no fornecimento de insumos básicos, como também atingirá a força de trabalho, a importação de produtos e o recolhimento de impostos (COOPER et al., 2001; CUNHA; CUNHA, 2005).

A sustentabilidade social resulta das interações nas relações sociais entre visitantes, empresários, instituições e comunidade local. Compreende a busca de um patamar razoável de homogeneidade social, distribuição de renda justa, emprego pleno ou autônomo com qualidade de vida decente e igualdade no acesso aos recursos e aos serviços sociais. A prática do turismo sustentável deve favorecer o fortalecimento do capital social, minimizar as tensões entre residentes e turistas e entre residentes e a própria atividade. A maior ou menor aprovação por parte da comunidade vai depender das mudanças sociais proporcionadas aos habitantes locais (SACHS, 2002; HANAI, 2009; BARDDAL, 2010).

O Ministério do Turismo (2007) agrega as dimensões cultural e social em uma única e a chama de sustentabilidade sociocultural. Neste contexto, a sustentabilidade sociocultural é um processo que visa à melhoria da qualidade de vida e à redução dos níveis de exclusão social por meio de uma distribuição mais justa da renda e dos bens.

Em se tratando das empresas ligadas ao setor turístico, em especial os meios de hospedagem, buscar benefícios de longo prazo; assegurar os compromissos da imagem corporativa, das relações de trabalho em seu quadro profissional; e minimizar o impacto ambiental de suas atividades em sua região de inserção e no ambiente global constituem parâmetros essenciais de sustentabilidade. Considera-se neste trabalho que o termo turismo sustentável deve estar vinculado à sustentabilidade das condições que dão suporte à atividade, ou seja, à sustentabilidade dos recursos naturais e das condições sociais e culturais do destino. 


\section{SUSTENTABILIDADE NOS MEIOS DE HOSPEDAGEM}

A expansão do fluxo de viagens, tanto domésticas quanto internacionais, aconteceu de forma extraordinária desde a década de 1950, quando passou de 25 milhões de desembarques internacionais para pouco mais de 1 bilhão de desembarques no ano de 2013. O volume de negócios, associados ao fluxo turístico, também aumentou significativamente, sendo o setor responsável por 1 de cada 11 empregos gerados, $6 \%$ das exportações mundiais e por $9 \%$ do PIB mundial (efeito direto, indireto e induzido) (Mtur, 2014). Tal crescimento do setor suscitou preocupações e intervenções em toda a cadeia turística no sentido de garantir eficiência, qualidade e adequação às implicações sociais, econômicas e ambientais inerentes à atividade.

Nesta perspectiva, a rede hoteleira faz parte de um segmento de mercado também em expansão e passou a incorporar procedimentos e padrões de conduta em razão do apelo ambientalista. A partir das preocupações que emergiram com o conceito de desenvolvimento sustentável, os meios de hospedagem passaram a ter atitudes menos danosas ao ambiente por meio da reavaliação de suas ações e da conscientização de seus colaboradores. Essa nova postura se dá por meio da otimização do uso dos recursos, do reaproveitamento e da reciclagem dos resíduos, maneiras simples de repensar o processo e tentar racionalizá-lo. Em função da contenção do desperdício, economizam-se os custos operacionais, crescem as oportunidades de mercado derivados das novas práticas ambientais, a imagem da corporação é fortalecida, além de causar um impacto positivo no moral dos empregados, aumentando o comprometimento dos clientes internos e o orgulho em ser parte da corporação (ENZ; SINGUAW, 1999; MALTA; MARIANI, 2013).

Em Valente (2007) encontra-se registrado que a rede hoteleira da Europa desde a década de 1980 utiliza técnicas para minimizar o uso da água e da energia elétrica. No ano de 1996 surgiu também na Europa a norma ISO 14001, voltada à gestão ambiental, o que vai nortear a partir de então todas as ações empresariais, inclusive nos meios de hospedagem, para o uso adequado dos recursos e redução dos impactos ambientais. 
Segundo Butler (2008), algumas das principais marcas do setor, como Marriott, Hilton, Fairmont e Starwood, também desenvolveram iniciativas e programas ambientais que buscam minimizar os impactos de suas operações. O autor afirma que, apesar de ainda ser incipiente o desenvolvimento sustentável na indústria hoteleira, essas tendências levarão ao desenvolvimento de "hotéis verdes" e, aqueles que adotarem posturas ambientalmente corretas voluntariamente, antes que elas se tornem normas impostas, serão recompensados pelo mercado.

De acordo com a pesquisa de Peres Jr. e Rezende (2011), a gestão da sustentabilidade na hotelaria tem sido objeto de estudos em várias partes do mundo: Espanha (ÁLVAREZ-GIL; BURGOS-GIMENEZ; CÉSPEDES-LORENTE, 2001; MOLINA-AZORÍN et al., 2009); Tailândia (HENDERSON, 2007); Turquia (TOSUN, 2001; ERDOGAN; BARIS, 2007); Suécia e Polônia (BOHDANOWICZ, 2006); Vietnã (LE et al., 2006) e China (CHAN, 2005).

No entanto, existem indícios de que o caminho ainda é longo para o alcance de um estágio razoável de sustentabilidade no setor hoteleiro. Swarbrooke (2000, p.31) apresenta uma visão mais pessimista e afirma que, em termos gerais, a indústria turística está excessivamente interessada nos lucros em curto prazo, está mais interessada em explorar o meio ambiente e as populações locais que em conservá-las, está cada vez mais controlada por grandes corporações transnacionais, não fazem o suficiente para aumentar a percepção dos turistas em prol da sustentabilidade e somente sobe no palanque do turismo sustentável quando há perspectiva de obter boa publicidade e de reduzir custos.

No Brasil, de acordo com o Conselho Nacional da Reserva da Biosfera da Mata Atlântica (RBMA, 2010), foi criado em 2003 o Conselho Brasileiro de Turismo Sustentável (CBTS). Neste momento foram estabelecidos os princípios que constituem a referência nacional para o turismo sustentável. Em 2004 surgiu o Programa de Certificação em Turismo Sustentável (PCTS), do Instituto de Hospitalidade, que juntamente com outros diversos parceiros, inclusive a RBMA, foi responsável pela criação da ABNT NBR 15.401 - Meios de Hospedagem - Sistema de Gestão de Sustentabilidade (Requisitos), que traz parâmetros objetivos e verificáveis relativos à sustentabilidade de hotéis e pousadas, ou seja, ao "uso de recursos de maneira ambientalmente responsável, socialmente justa e economicamente viável". 
Estudos no Brasil foram realizados no sentido de investigar a respeito das condições apresentadas pelos meios de hospedagem quanto à responsabilidade socioambiental e gestão da sustentabilidade dos mesmos. A partir de uma revisão bibliográfica, verificou-se trabalhos em Monte Verde - MG (PERES; REZENDE, 2011); Garopaba - SC (ASSUNÇÃO et al., 2013); Torres - RS (MELLO et al., 2012); Campo Grande - MS (MALTA; MARIANI, 2013); Natal - RN (VIRGINIO; FERNANDES, 2011).

Em Monte Verde - MG, Peres Jr. e Rezende (2011) utilizaram metodologia específica para calcular o Índice Geral de Gestão da Sustentabilidade (IGGS) nos empreendimentos hoteleiros pesquisados, baseado em 24 indicadores. O valor do índice obtido demonstra que, em Monte Verde, ainda é muito incipiente a adoção de práticas de gestão da sustentabilidade.

Em Campo Grande (MS), comparando as normas que envolvem a sustentabilidade com as ações dos hotéis investigados, Malta e Mariani (2013) afirmam que as práticas de sustentabilidade são incipientes e isoladas, determinadas principalmente por leis ou por economia comprovada sem grandes esforços. Segundo os autores, o perfil da sustentabilidade nos hotéis de Campo Grande mostra-se em fase inicial e ainda ressaltam que os aspectos culturais foram os mais negligenciados.

Mello et al. (2012), em pesquisa realizada no município de Torres, litoral norte do Rio Grande do Sul, afirma que ainda é muito reduzido o grau de conscientizaçãotanto degestores quanto de colaboradores dosestabelecimentos hoteleiros ali instalados. Da mesma forma, os hóspedes não se mostram muito sensibilizados ou preocupados com as práticas de sustentabilidade.

Algumas experiências positivas em termos de conservação ambiental e redução dos impactos, ainda que iniciais e tímidas, acontecem nos empreendimentos hoteleiros em Garopaba e Imbituba em Santa Catarina (ASSUNÇÃO et al., 2013) e na via costeira de Natal, onde os estabelecimentos pesquisados foram considerados como organizações social e ambientalmente responsáveis (VIRGINIO; FERNANDES, 2011). 


\section{PROCEDIMENTOS METODOLÓGICOS}

A pesquisa caracterizou-se por seu caráter descritivo e exploratório quanto as seus objetivos. O caráter descritivo cria condições para descobrir e observar os fenômenos, procurando descrevê-los, classificá-los e interpretá-los e estabelecer relações entre as variáveis de estudo. É também uma pesquisa exploratória no sentido de levantar dados e problemas que podem servir de apoio a pesquisas futuras mais avançadas (RUDIO, 1986; RUIZ, 2006; VIEIRA, 2010).

Quantos aos procedimentos, a pesquisa teve uma abordagem tanto qualitativa quanto quantitativa. Na forma qualitativa, consta da pesquisa bibliográfica e do levantamento tipo survey, visando coletar os dados por meio da aplicação de questionário. O questionário buscou, por meio da utilização de uma escala adaptada de Likert, verificar o grau de utilização de práticas relacionadas à da sustentabilidade nos meios de hospedagem. Nos procedimentos quantitativos foram utilizadas técnicas de análise estatística descritiva.

O instrumento de coleta de dados foi baseado na coleta de dados primários obtidos por meio de aplicação de questionários aos gestores e aos funcionários de 40 meios de hospedagem, sendo a amostra do tipo não probabilística por acessibilidade, no período de 27 de dezembro de 2011 a 10 de janeiro de 2012, no povoado de Barra Grande, comunidade localizada nos limites do município de Maraú (BA), em uma península que leva o nome deste município, no entorno da Baía de Camamu, fazendo parte do Território Litoral Sul da Bahia e dentro da Zona Turística denominada Costa do Dendê.

Os respondentes foram abordados em seus estabelecimentos no horário comercial ou em outro horário e local a seu pedido. As condições oferecidas pelo setor hoteleiro para um turismo sustentável na comunidade de Barra Grande foram avaliadas por meio de indicadores objetivos e subjetivos baseados no funcionamento do estabelecimento e no comportamento de visitantes e funcionários.

Os indicadores selecionados foram baseados nos trabalhos de Gomes (2005) e Hanai (2009) e também a partir de elaboração própria. Foram operacionalizados 
a partir de uma escala Lickert, variando de " 0 " a "4" pontos, em que a nota " 0 " foi considerada a pior situação possível e a nota " 4 " a melhor situação desejável dentro do contexto de cada indicador. O Quadro 2 apresenta a matriz de indicadores com seus objetivos e fontes de referência.

Após análise descritiva dos resultados encontrados, pautados nos indicadores selecionados, foi pensada a criação de um índice para sintetizar tais informações e representar as condições vigentes dos meios de hospedagem em um contexto de sustentabilidade. O Índice de Sustentabilidade Hoteleira (ISH) foi obtido pelo somatório do valor médio de cada indicador $(\bar{I})$ dividido pelo valor máximo possível (V) para a sustentabilidade hoteleira, dado por:

$I S H=\frac{\sum \bar{I}}{V}$

onde,

ISH = índice de sustentabilidade hoteleira;

$\bar{I}=$ valor médio de cada indicador

$\mathrm{V}=$ valor máximo possível da sustentabilidade hoteleira $(=80)$. Permite estabelecer o índice em uma escala de valor entre 0,00 e 1,00.

A classificação do grau de sustentabilidade do setor hoteleiro no povoado de Barra Grande foi estabelecida em cinco níveis, de acordo com o Quadro 1.

Quadro 1 - Escala de classificação do Índice de Sustentabilidade Hoteleira

\begin{tabular}{|c|c|}
\hline Faixa & Classificação \\
\hline $0,00<\mathrm{X} \leq 0,20$ & Condição totalmente insatisfatória \\
\hline $0,20<\mathrm{X} \leq 0,40$ & Condição Insatisfatória \\
\hline $0,40<\mathrm{X} \leq 0,60$ & Condição moderada de sustentabilidade \\
\hline $0,60<\mathrm{X} \leq 0,80$ & Condição satisfatória \\
\hline $0,80<\mathrm{X} \leq 1,00$ & Condição ótima de sustentabilidade \\
\hline
\end{tabular}

Fonte: Elaboração própria. 


\section{Quadro 2 - Matriz de Indicadores de Sustentabilidade para o setor hoteleiro em}

Barra Grande, Maraú - BA

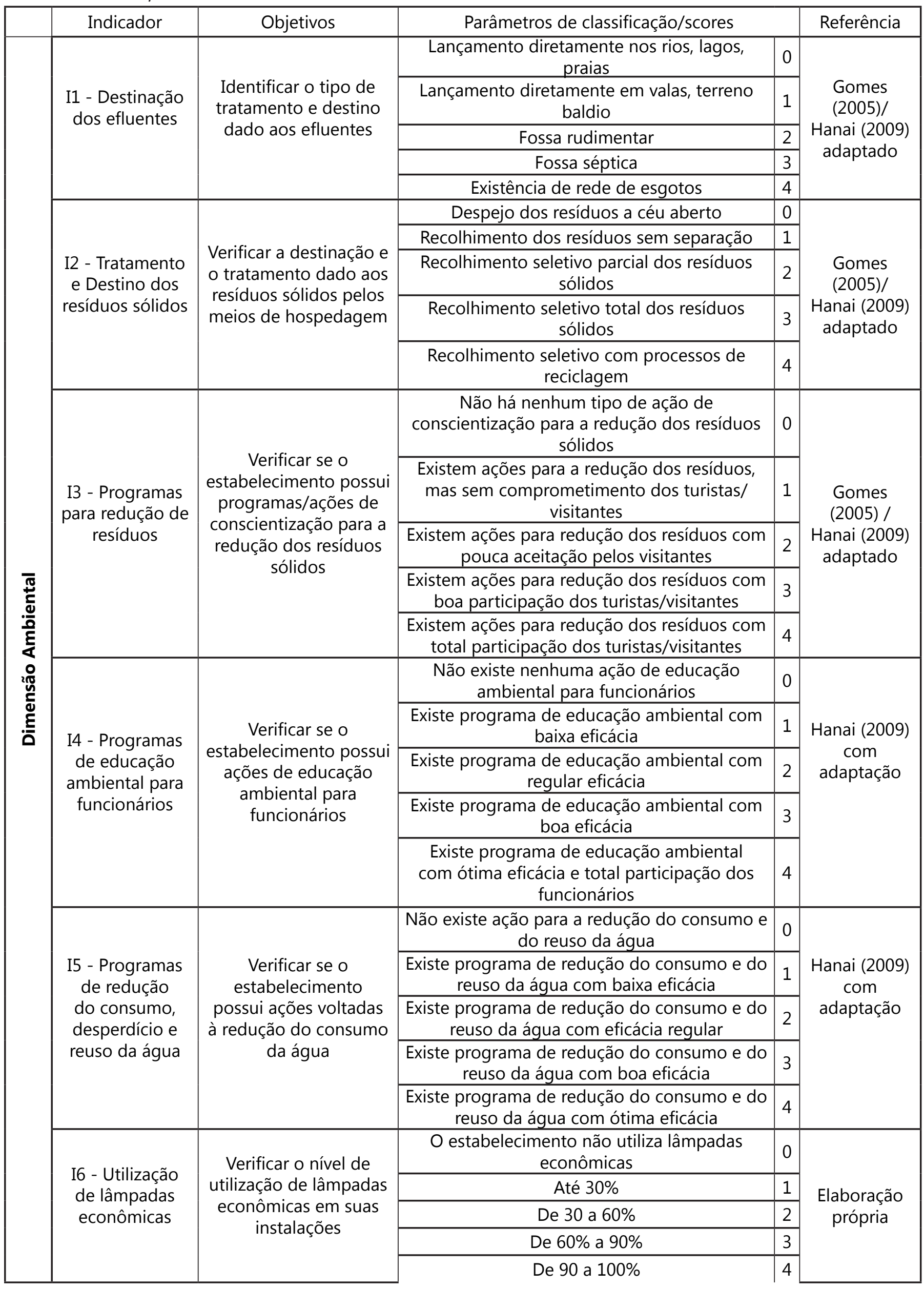


DoI: 10.14210/rtva.v17n3.p601-629

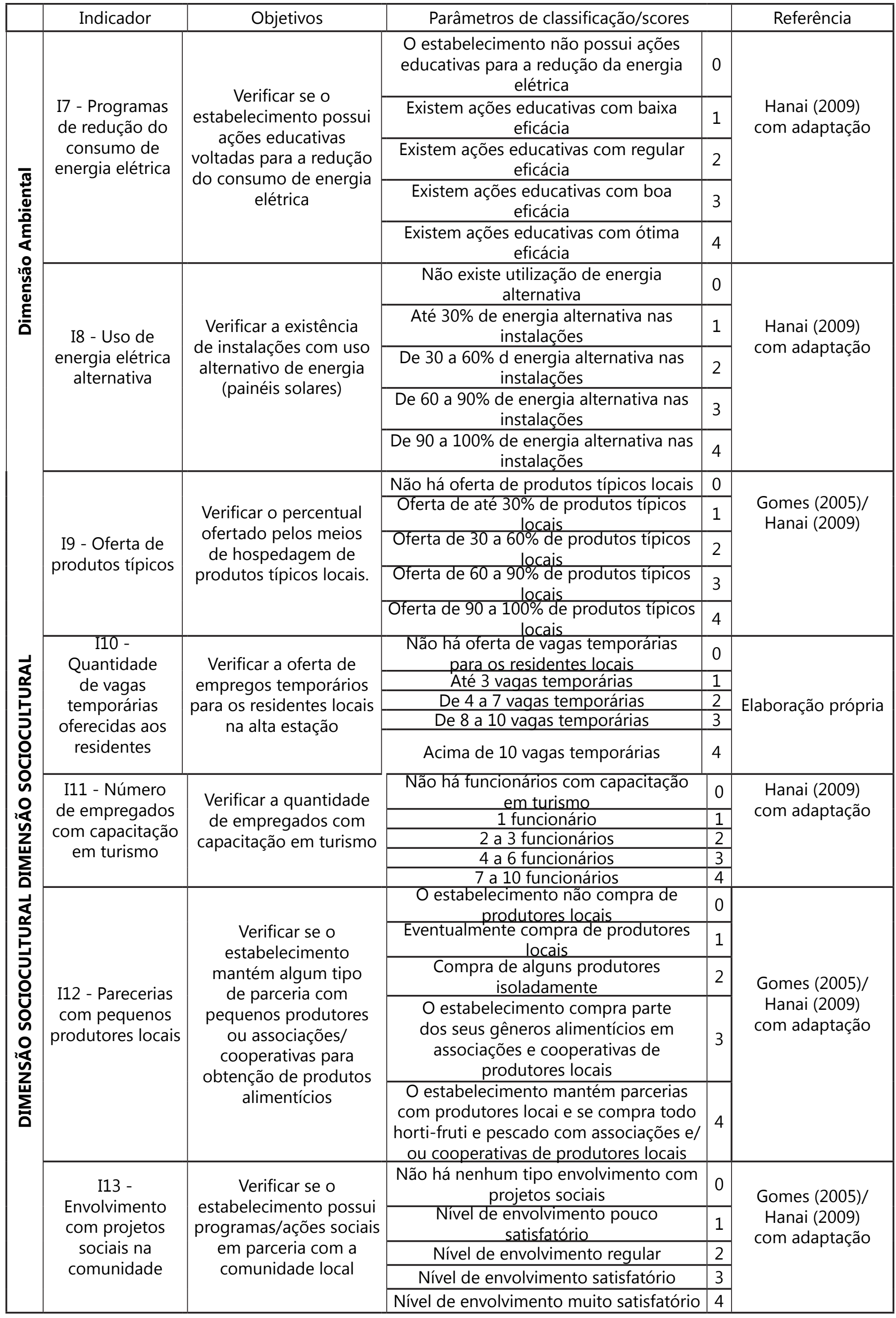




\begin{tabular}{|c|c|c|c|c|c|}
\hline & Indicador & Objetivos & \multicolumn{2}{|l|}{ Parâmetros de classificação/scores } & Referencia \\
\hline & \multirow{5}{*}{$\begin{array}{l}\text { I14 - Acessibilidade } \\
\text { para pessoas com } \\
\text { dificuldade de } \\
\text { locomoção }\end{array}$} & \multirow{5}{*}{$\begin{array}{l}\text { Verificar a existência } \\
\text { e a preocupação do } \\
\text { estabelecimento com a } \\
\text { mobilidade e o acesso }\end{array}$} & $\begin{array}{l}\text { O estabelecimento não dispõe no momento } \\
\text { de facilidades para a mobilidade e acesso }\end{array}$ & 0 & \multirow{5}{*}{$\begin{array}{c}\text { Gomes } \\
\text { (2005)/ } \\
\text { Hanai } \\
\text { (2009) } \\
\text { com } \\
\text { adaptação }\end{array}$} \\
\hline & & & $\begin{array}{l}\text { Existe a perspectiva de adaptar as } \\
\text { instalações para esse fim }\end{array}$ & 1 & \\
\hline & & & $\begin{array}{c}\text { Existem facilidades para o acesso à entrada } \\
\text { do estabelecimento }\end{array}$ & 2 & \\
\hline & & & $\begin{array}{c}\text { Existem facilidades para o acesso e } \\
\text { mobilidade por entre o estabelecimento }\end{array}$ & 3 & \\
\hline & & & $\begin{array}{l}\text { Existe facilidade para o acesso, mobilidade } \\
\text { e adaptações em todas as instalações do } \\
\text { estabelecimento }\end{array}$ & 4 & \\
\hline & & & Até 1 ano & 0 & Gomes \\
\hline & Longevidade do & Verificar o tempo de & 1 a 3 anos & 1 & (2005) \\
\hline & estabelecimento & $\begin{array}{l}\text { permanencia e atuaçao } \\
\text { do estabelecimento }\end{array}$ & 4 a 7 anos & 2 & $\begin{array}{l}\text { Hanal } \\
\text { (2009) }\end{array}$ \\
\hline & & & 8 a 10 anos & 3 & \\
\hline & & & Acima de 10 anos & 4 & adaptação \\
\hline & & & Ocupação média até $20 \%$ & 0 & \\
\hline & I16 - Taxa de & de ocupação das & De 20 a $40 \%$ & 1 & Hanai \\
\hline & ocupação média & instalações do & De 40 a $60 \%$ & 2 & $\begin{array}{c}(2009) \\
\text { com }\end{array}$ \\
\hline & na alta estação & estabelecimento na alta & De 60 a $80 \%$ & 3 & adaptação \\
\hline & & & De 80 a $100 \%$ & 4 & \\
\hline & & Verificar & Ocupação média até $20 \%$ & 0 & Hanai \\
\hline & I17 - Taxa de & de ocupação das & De 20 a $40 \%$ & 1 & (2009) \\
\hline & ocupação média & instalações do & De 40 a $60 \%$ & 2 & com \\
\hline & na baixa estação & estabelecimento na & De 60 a $80 \%$ & 3 & adaptação \\
\hline & & & De 80 a $100 \%$ & 4 & \\
\hline$\cdot \frac{\mathbb{U}}{\xi}$ & & & $\begin{array}{c}\text { Não há estratégias que permitam o } \\
\text { funcionamento do empreendimento na } \\
\text { baixa estação }\end{array}$ & 0 & \\
\hline 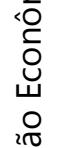 & & Verificar a existência & $\begin{array}{c}\text { Não há estratégias, o empreendimento } \\
\text { funciona com pessoal e instalações } \\
\text { reduzidas }\end{array}$ & 1 & Gomes \\
\hline$\stackrel{\mathscr{c}}{\frac{N}{\mathscr{c}}}$ & $\begin{array}{l}\text { I18 - Estratégias } \\
\text { para a } \\
\text { sazonalidade }\end{array}$ & $\begin{array}{l}\text { de estratégias para } \\
\text { enfrentar os efeitos da } \\
\text { sazonalidade }\end{array}$ & $\begin{array}{c}\text { O empreendimento funciona e pretende } \\
\text { desenvolver estratégias para minimizar os } \\
\text { efeitos da sazonalidade }\end{array}$ & 2 & $\begin{array}{l}\text { (2005) } \\
\text { Hanai } \\
(2009) \\
\text { com }\end{array}$ \\
\hline & & & $\begin{array}{c}\text { O estabelecimento já desenvolve } \\
\text { estratégias de marketing para minimizar os } \\
\text { efeitos da sazonalidade }\end{array}$ & 3 & adaptação \\
\hline & & & $\begin{array}{c}\text { O estabelecimento já desenvolve } \\
\text { estratégias com resultados satisfatórios } \\
\text { quanto à sazonalidade }\end{array}$ & 4 & \\
\hline & & & Totalmente insatisfatório & 0 & \\
\hline & Lucratividade do & Verificar o grau de & Insatisfatório & 1 & \\
\hline & empreendimento & $\begin{array}{l}\text { Iucratividade dos meios } \\
\text { de hospedagem }\end{array}$ & Baixa lucratividade & 2 & $\begin{array}{l}\text { Elaboraçao } \\
\text { própria }\end{array}$ \\
\hline & hoteleiro & & Suficiente para manter o funcionamento & 3 & \\
\hline & & & Totalmente satisfatório/excelente & 4 & \\
\hline & & & Não existe planejamento & 0 & \\
\hline & I20 - & & Existe eventualmente - informal & 1 & \\
\hline & Planejamento do & & Realizado 1 vez nos últimos 5 anos & 2 & Elaboração \\
\hline & empreendim & & Realizado 2 vezes nos últimos 5 anos & 3 & própria \\
\hline & & & Existe planejamento regular (anual) & 4 & \\
\hline
\end{tabular}




\section{AVALIAÇÃO DOS INDICADORES DE SUSTENTABILIDADE PARA O TURISMO EM BARRA GRANDE}

Esta seção destaca as condições e a contribuição do setor hoteleiro para o desenvolvimento do turismo sustentável no destino Barra Grande, em Maraú (BA), a partir das informações operacionais dos estabelecimentos, prestadas pelos proprietários e pelos gestores. A primeira parte desta análise trata da avaliação dos indicadores de sustentabilidade selecionados para os meios de hospedagem. Em seguida, a partir das notas obtidas pelos indicadores, será apresentado o Índice de Sustentabilidade Hoteleira (ISH) para a localidade estudada, na tentativa de evidenciar o estágio no qual se encontram os empreendimentos pesquisados.

Dos 40 meios de hospedagem pesquisados, $87,5 \%$ foi do tipo pousada, a maior parte concentrando-se no centro da vila. A Tabela 1 apresenta a avaliação dos indicadores, revelando condições ainda insatisfatórias para um nível de sustentabilidade adequado por parte do setor hoteleiro, seja por conta da própria condição do lugar, seja por falta de práticas sustentáveis naqueles estabelecimentos. Dentre os 20 indicadores avaliados, 13 situaram-se abaixo da faixa de pontuação mediana (nota 2).

Tabela 1 - Indicadores de sustentabilidade para os meios de hospedagem localizados na Vila de Barra Grande, município de Maraú -BA , dezembro 2011/janeiro 2012

\begin{tabular}{|c|c|c|c|c|}
\hline Dimensão & & Indicador & Nota média & Posição \\
\hline \multirow{8}{*}{ Ambiental } & I1 & Destinação resíduos & 2,35 & $5^{\circ}$ \\
\hline & I2 & Destinação efluentes & 2,28 & $6^{\circ}$ \\
\hline & I3 & Conscientização para redução resíduos & 1,15 & $10^{\circ}$ \\
\hline & I4 & Educação ambiental para funcionários & 0,73 & $15^{\circ}$ \\
\hline & I5 & Redução do consumo e do reuso da água & 0,98 & $13^{\circ}$ \\
\hline & I6 & Utilização de lâmpadas econômicas & 3,33 & $2^{\circ}$ \\
\hline & I7 & Redução do consumo de energia elétrica & 1,03 & $12^{\circ}$ \\
\hline & I8 & Uso de painel solar & 0,45 & $20^{\circ}$ \\
\hline \multirow{6}{*}{ Sociocultural } & 19 & Facilidades para mobilidade & 0,75 & $14^{\circ}$ \\
\hline & I10 & Produtos típicos & 1,78 & $9^{\circ}$ \\
\hline & I11 & Empregados de origem local & 2,38 & $4^{\circ}$ \\
\hline & I12 & Capacitação turismo & 0,7 & $16^{\circ}$ \\
\hline & I13 & Parcerias com produtores locais & 0,63 & $17^{\circ}$ \\
\hline & I14 & Projetos sociais com a comunidade & 0,55 & $18^{\circ}$ \\
\hline
\end{tabular}




\begin{tabular}{l|l|c|c|c}
\hline \multirow{*}{*}{ Econômica } & I15 & Tempo de funcionamento & 2,83 & $3^{\circ}$ \\
\cline { 2 - 2 } & I16 & Taxa de ocupação na alta estação & 3,85 & $1^{\circ}$ \\
\cline { 2 - 4 } & I17 & Taxa de ocupação na baixa estação & 0,5 & $19^{\circ}$ \\
\cline { 2 - 5 } & I18 & Estratégias para enfrentar sazonalidade & 1,1 & $11^{\circ}$ \\
\cline { 2 - 5 } & I19 & Lucratividade do empreendimento & 2,18 & $7^{\circ}$ \\
\cline { 2 - 5 } & I20 & Planejamento do empreendimento & 1,93 & $8^{\circ}$ \\
\hline
\end{tabular}

Fonte: Dados da pesquisa.

A Tabela 1 também permite visualizar que os três indicadores melhores avaliados foram aqueles relacionados com a "taxa de ocupação na alta estação" na dimensão econômica, "utilização de lampadas econômicas" na dimensão ambiental e "tempo de funcionamento" do empreendimento também na dimensão econômica. A taxa de ocupação em Barra Grande na alta estação sempre foi elevada em razão dos seus atrativos naturais e, assim, viabiliza oportunidades de ganhos econômicos, condição necessária para o fortalecimento da dimensão econômica da sustentabilidade (COOPER et al., 2001; CUNHA; CUNHA, 2005; MTur, 2007; OMT, 2005). Entretanto, o aumento do fluxo de visitantes combinado com uma infraestrutura inadequada poderá comprometer a capacidade de suporte da localidade. Quanto às lampadas econômicas, mesmo reconhecendo que seu uso minimiza os impactos decorrentes do consumo de energa elétrica, a motivação é essencialmente para a redução dos custos.

Constatou-se durante a pesquisa que a localidade não dispõe de rede pública de esgotos, fato este que deprecia as condições sanitárias do destino e a dimensão ambiental dos indicadores, especialmente no tocante ao adequado destino dos efluentes que ficam sob a responsabilidade dos empreendimentos. Apenas $28 \%$ das pousadas pesquisadas declararam utilizar fossa séptica, enquanto o restante faz uso da fossa rudimentar sem nenhum tipo de tratamento. Essa condição impõe riscos à qualidade e ao fornecimento dos serviços ambientais que estão intimamente ligados ao turismo, em decorrência do uso do solo, da vegetação e dos recursos hídricos, como explicita autores como Barddal (2010), Cunha e Cunha (2005), Dias (2003) e Ruschmann (2000). Quanto aos resíduos sólidos gerados no estabelecimento, já existe uma preocupação com o tratamento a ser dado, pois, de acordo com as informações prestadas, verificou-se que 
em $50 \%$ dos meios de hospedagem existem recolhimento seletivo parcial dos resíduos e em $42,5 \%$ há o recolhimento seletivo total dos resíduos. Em 7,5\% existe o recolhimento sem separação seletiva.

Faltam também ações educativas e de conscientização por parte do setor hoteleiro para minimizar os possíveis impactos ambientais provenientes do consumo de funcionários e turistas nos estabelecimentos. Em 45\% dos estabelecimentos não existem nenhuma ação de conscientização para reduzir a geração de resíduos e, naqueles que informaram possuir tais ações, em 17,5\% não há comprometimento dos turistas e em $15 \%$ existe pouca participação, ou seja, apesar de existir o esforço por parte do setor hoteleiro, não há um efetivo envolvimento dos turistas em reduzir sua geração de resíduos. Os números mostram uma situação que vai na direção oposta à concepção de desenvolvimento turístico sustentável preconizada por Irving et al. (2005), que destacam a importância do turista consciente e dos seus possíveis impactos ambientais.

Também não foram evidenciados resultados satisfatórios quanto à redução e ao reuso da água nos meios de hospedagem, quando verificado que em $60 \%$ dos estabelecimentos pesquisados não existem ações para este fim. Dentre aqueles estabelecimentos (40\%) que declararam existir ações para a redução do consumo e reuso da água, 7,5\% apresentaram resultados "insatisfatórios" e $32,5 \%$ apresentam resultados "pouco satisfatórios". Embora os indicadores que remetem à redução dos impactos do turismo situem-se ainda em um patamar distante de uma condição ideal de sustentabilidade, nota-se que as iniciativas já existem em pelo menos $40 \%$ dos meios de hospedagem pesquisados e cujo sucesso depende em grande parte das atitudes e da colaboração dos funcionários e dos visitantes.

Na dimensão sociocultural, todos os indicadores específicos do setor hoteleiro obtiveram nota abaixo de 3 , ou seja, abaixo de uma pontuação considerada satisfatória. Os piores indicadores avaliados foram o "nível de parcerias com produtores locais", com nota média de 0,63, e o "nível de envolvimento com projetos sociais na comunidade", com nota média de 0,55. Tais indicadores mostram um baixíssimo nível de interação do setor hoteleiro com a comunidade, sugerindo um distanciamento do empresariado com a realidade da população. 
É por meio destas interações entre visitantes, empresários e comunidade local que reside a essência e a base da sustentabilidade social. A ausência dessa condição pode favorecer o surgimento de tensões entre residentes e turistas e entre residentes e a própria atividade (BARDDAL, 2010; SACHS, 2002).

Quanto aos produtos ofertados pelos meios de hospedagem aos visitantes, constatou-se que $82,5 \%$ dos estabelecimentos pesquisados disponibilizam pelo menos $30 \%$ de produtos de origem local. A maior proporção $(27,5 \%)$ é formada pelos estabelecimentos que informaram ofertar de $30 \%$ a $60 \%$ de produtos típicos. Em certa medida, percebe-se que esse número de pousadas e hotéis que ofertam produtos locais para os visitantes contribuem para a valorização da cultura local. A sustentabilidade cultural, da forma como Barddal (2010) explica, está alicerçada na manutenção dos valores locais, do patrimônio cultural local, seja ele material ou imaterial e deve, assim, valorizar os produtos típicos que são produzidos pela comunidade como artesanatos e alimentos que retratam a identidade da população com o lugar.

É importante observar que o indicador melhor pontuado nesta dimensão foi o número de "empregados de origem local" no estabelecimento que obteve nota 2,38. Apenas três das pousadas pesquisadas (7,5\%) informaram não possuir empregados nativos, as demais possuíam no mínimo 30\% de residentes de origem local em seus quadros. Em $50 \%$ dos meios de hospedagem pesquisados a proporção de funcionários oriundos da própria comunidade representou entre $50 \%$ a $80 \%$ do quadro de pessoal, significando importante contribuição na redução dos níveis de exclusão social e na distribuição da riqueza gerada no destino (MINISTÉRIO DO TURISMO, 2007).

Outro fator importante para o desenvolvimento da atividade turística é que o destino ofereça um conjunto de equipamentos e serviços composto por um quadro de pessoal qualificado para receber e atender o visitante. A avaliação do indicador "capacitação em turismo" constatou que em 55\% dos estabelecimentos pesquisados não há funcionários com capacitação em turismo, conforme observado na Figura 1 . Em $25 \%$ dos meios de hospedagem pesquisados, existem até $25 \%$ do total de funcionários possuindo capacitação em turismo, $15 \%$ dos estabelecimentos possuem até $50 \%$ e apenas $5 \%$ têm no seu quadro 
de pessoal até $75 \%$ de funcionários com capacitação em turismo. Os dados servem de alerta para uma situação que pode comprometer o desenvolvimento do turismo na Vila de Barra Grande, haja vista que a falta de pessoal qualificado pode influenciar na permanência e no retorno do visitante.

Figura 1 - Proporção de funcionários dos meios de hospedagem com capacitação em turismo na Vila de Barra Grande, município de Maraú - BA, dez 2011/jan 2012

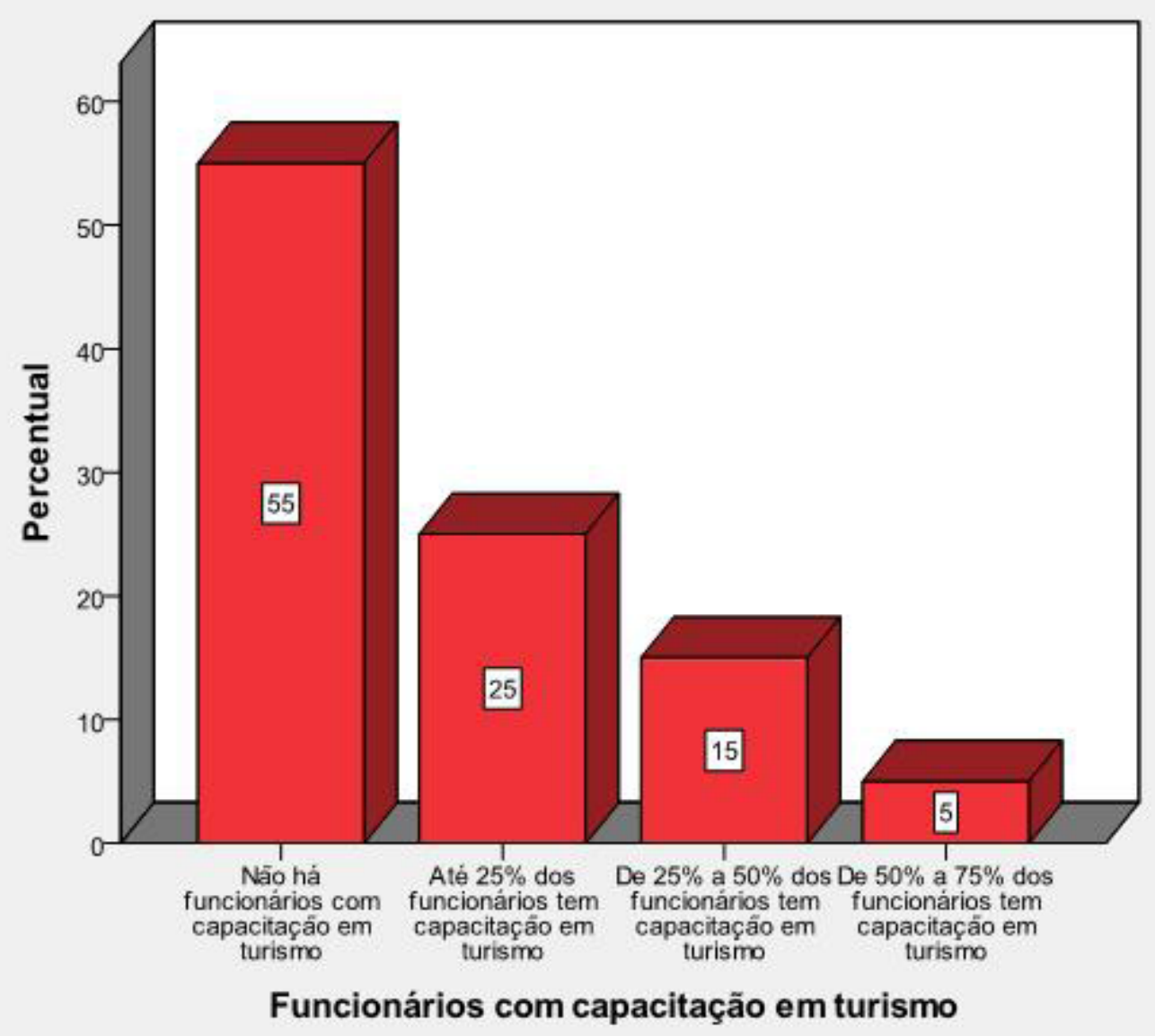

O indicador "vagas temporárias de trabalho" objetivou medir a absorção dos residentes de origem local pelos meios de hospedagem na alta estação, período em que o fluxo de turistas aumenta significativamente, o que requer a contratação de pessoal para atender às necesidades do estabelecimento em virtude do aumento da demanda. A Figura 2 apresenta os resultados deste levantamento indicando que em $92,5 \%$ nos meios de hospedagem pesquisados existem contratações do pessoal local. São oferecidas até 3 vagas temporárias em 37,5\% dos estabelecimentos e somente em $5 \%$ dos estabelecimentos são contratados em número acima de 10 pessoas da localidade. O número reduzido de contratações é justificado por conta 
do baixo nível de escolaridade e da falta de qualificação técnica da população de Barra Grande, de acorodo com os proprietários.

Figura 2 - Oferta de vagas temporárias de trabalho nos meios de hospedagem na Vila de Barra Grande, município de Maraú-BA, dezembro 2011/janeiro 2012

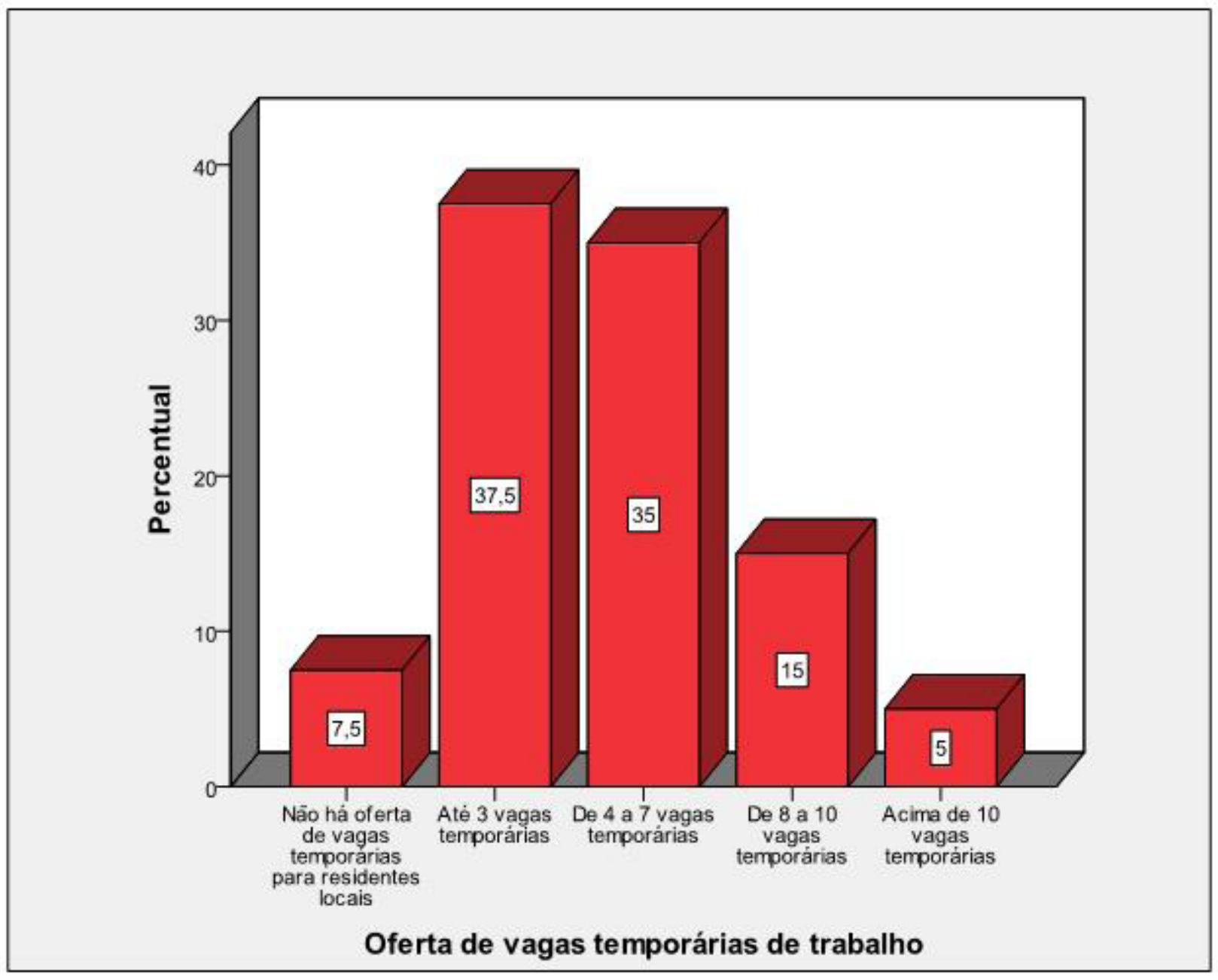

Fonte: Dados da pesquisa.

Na Dimensão Econômica, constatou-se por meio da análise das informações prestadas que o efeito da sazonalidade representa uma das maiores dificuldades para os empresários do setor. No verão, quase que a totalidade das pousadas pesquisadas encontra-se com todas as suas instalações ocupadas, com 85\% dos estabelecimentos registrando taxa de ocupação de 80 a 100\%. No entanto, na baixa estação, 92,5\% delas ocupam no máximo $40 \%$ dos leitos, sendo que destes, 57,5\% ocupam até 20\% (Figura 3), comprometendo significativamente a viabilidade econômica do negócio. 
Figura 3 - Taxa média de ocupação dos meios de hospedagem na baixa estação no povoado de Barra Grande, município de Maraú-BA, dezembro 2011/janeiro 2012

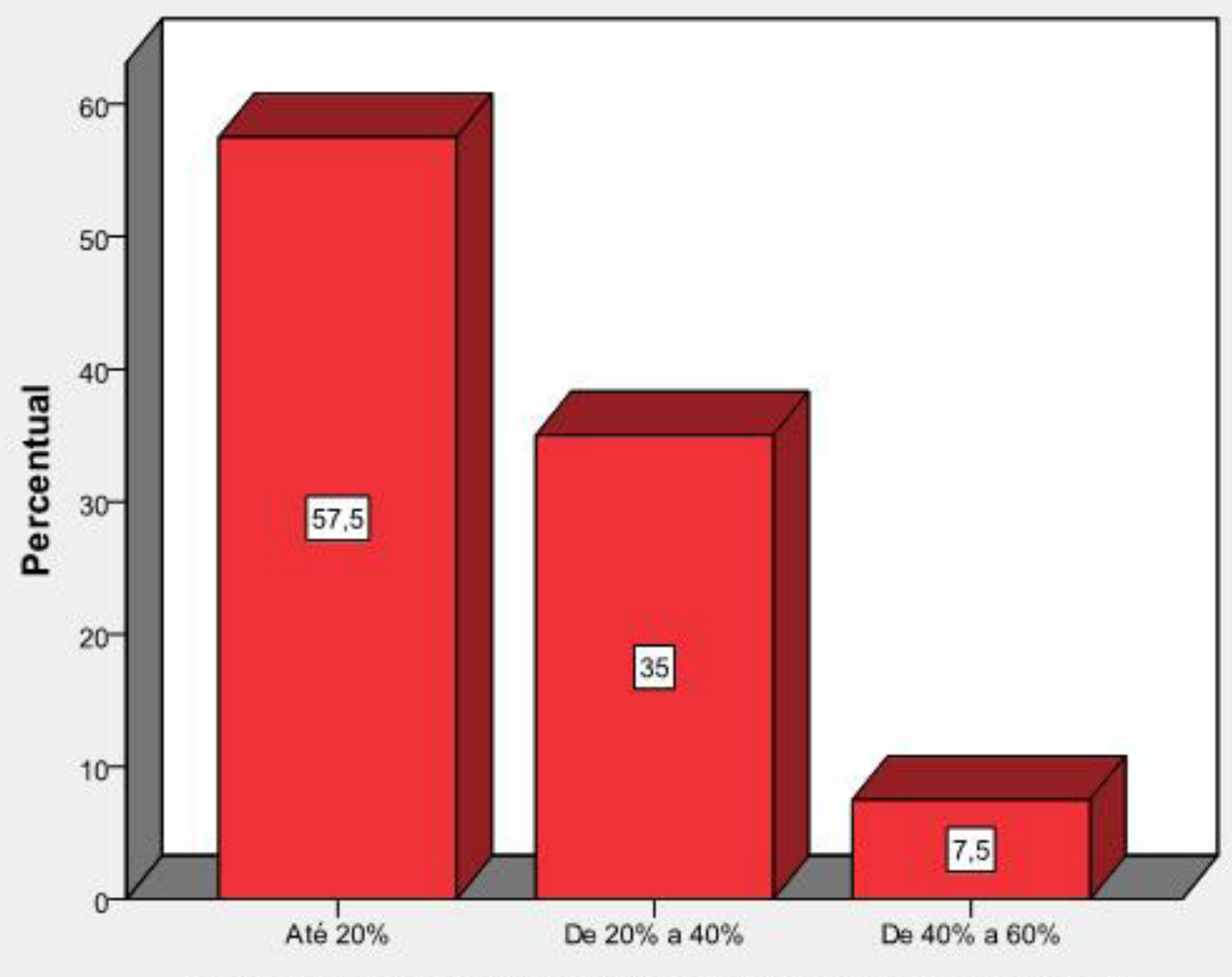

Taxa de ocuação do setor hoteleiro na baixa estação

Fonte: Dados da pesquisa.

Os problemas advindos da reduzida taxa de ocupação na baixa estação, a falta de estratégias para enfrentar a sazonalidade e a falta de planejamento do empreendimento comprometem consideravelmente a sustentabilidade econômica do setor hoteleiro com reflexos na lucratividade do empreendimento, o que explicaria a insatisfação com este indicador para $75 \%$ dos empreendimentos pesquisados e, nesta direção, compromete a garantia de operações econômicas viáveis para o setor, com repercussões em todo o trade turístico em Barra Grande.

\section{ÍNDICE DE SUSTENTABILIDADE HOTELEIRA}

A agregação das notas dos indicadores permitiu a elaboração do índice de sustentabilidade hoteleira (ISH). Assumindo valores entre 0 e 1, o índice poderá ser usado para avaliar o estágio do setor hoteleiro como agente de promoção 
do desenvolvimento sustentável em Barra Grande de acordo com as práticas adotadas naqueles estabelecimentos.

De acordo com os cálculos, o ISH alcançou um valor de 0,39, um valor muito baixo que, tendo como base o Quadro 1, representa um condição insatisfatória e sugere que a adoção de práticas sustentáveis por parte dos meios de hospedagem ainda é incipiente e pouco contribui para o desenvolvimento sustentável no destino.

A partir da pontuação obtida nos 20 indicadores avaliados em cada meio de hospedagem, foi possível estabelecer o índice para cada um dos empreendimentos pesquisados. A Figura 4 apresenta a distribuição percentual dos meios de hospedagem por valor de índice individual para os estabelecimentos e constatou-se que apenas $5 \%$ deles apresentaram um índice com valor entre 0,6 e 0,80, uma condição considerada satisfatória em termos de práticas sustentáveis adotadas.

A maioria da rede hoteleira em Barra Grande (65\%) obteve um valor para o índice em uma faixa entre 0,20 e 0,40, classificada dentro de uma condição insatisfatória e $30 \%$ dos meios de hospedagem situaram-se em uma faixa de pontuação entre 0,40 e 0,60, classificada como condição moderada de sustentabilidade hoteleira. 
Figura 4 - Índice de Sustentabilidade Hoteleira por estabelecimento, Vila de Barra Grande, distribuição percentual

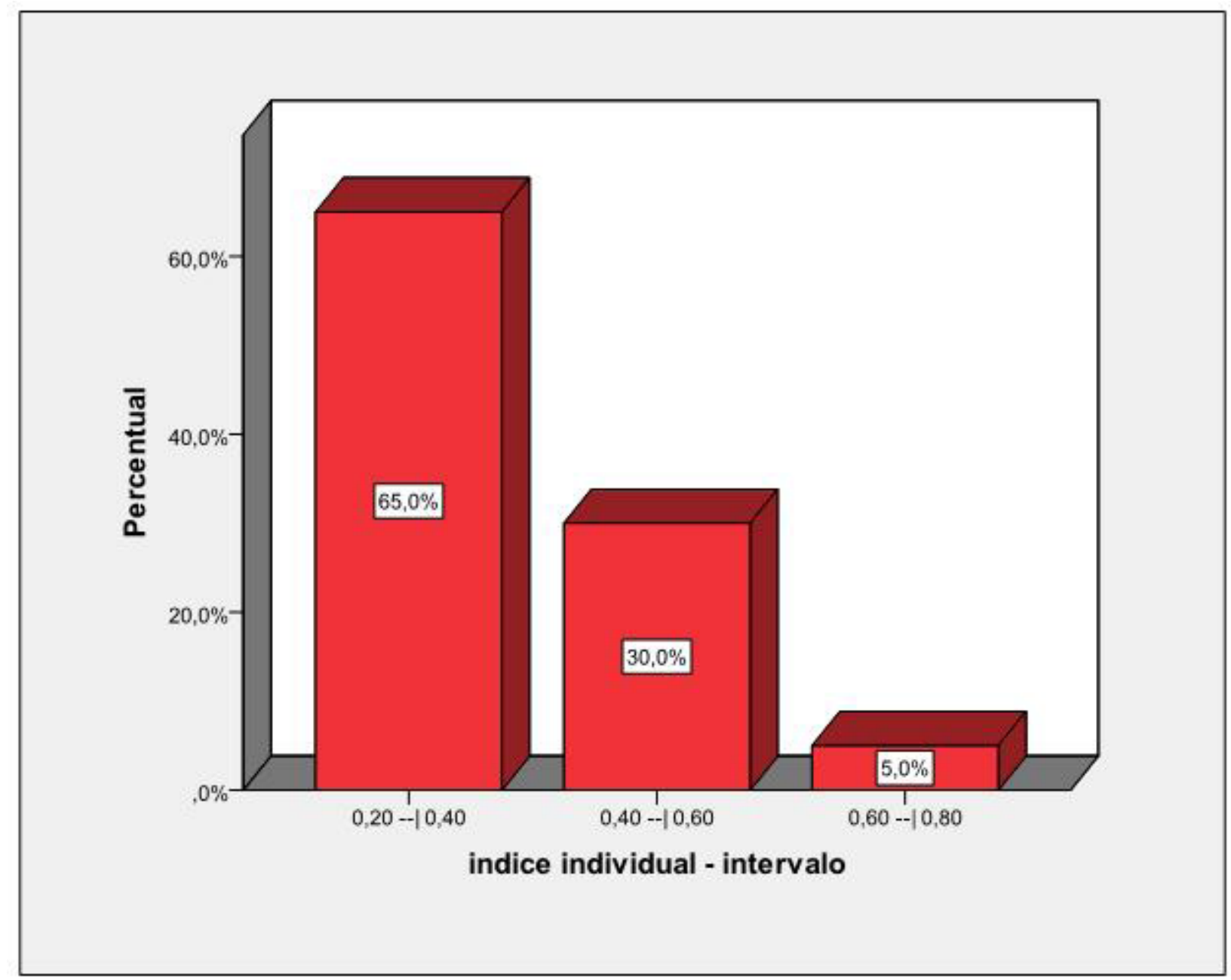

Fonte: Dados da pesquisa.

Enquanto o ISH, calculado de forma abrangente, verifica as condições sob as quais são adotadas práticas de sustentabilidade na rede hoteleira do destino em estudo, o índice individual, calculado para cada meio de hospedagem, permite conhecer o quanto cada estabelecimento está envolvido e contribui com o desenvolvimento sustentável adotando práticas sustentáveis de acordo com as dimensões ambiental, econômica e sociocultural. Nota-se que as condições encontradas em Barra Grande assemelham-se com outras localidades como foi em Monte Verde (MG), Campo Grande (MS), Torres (RS), de acordo com a literatura. Naqueles destinos a condução dos negócios ainda não contempla a sustentabilidade na gestão da atividade hoteleira, revelando níveis insatisfatórios de ações para o turismo sustentável. 
No caso de Barra Grande, em que pese as condições precárias em infraestrutura, há evidências a partir dos indicadores avaliados que são as condições operacionais dos próprios estabelecimentos que mais comprometem a sustentabilidade hoteleira na localidade, a exemplo da ausência de ações de conscientização dos funcionários e dos visitantes para o uso responsável dos recursos e minimização dos impactos, falta de facilidades para a mobilidade, carência de funcionários com capacitação em turismo e o não envolvimento com as questões locais e a exagerada dependência da alta estação para viabilizar o funcionamento das pousadas sem nenhum tipo de estratégia de marketing para o enfrentamento dos efeitos da sazonalidade.

\section{CONSIDERAÇÕES FINAIS}

A Vila de Barra Grande desfruta de uma condição geográfica privilegiada que Ihe confere características peculiares em atrativos naturais, despontando como um dos principais destinos turísticos do Litoral Sul da Bahia. Com um charme próprio de uma vila insular, o povoado encontra no turismo sua principal base econômica e para onde convergem todos os esforços locais para a obtenção dos benefícios econômicos proporcionados pela atividade. Nesta perspectiva, este trabalho objetivou avaliar as condições apresentadas pelos meios de hospedagem para o turismo sustentável do destino por meio da elaboração do índice de sustentabilidade hoteleira.

Na avaliação dessas condições, considerando um intervalo entre 0 e 1, obtevese o valor de 0,39 para o índice, o que sintetiza pontuações muito baixas para a maioria dos indicadores dentro das três dimensões analisadas (ambiental, sociocultural e econômica) e, assim, revela a fragilidade desses componentes para a adequação do setor hoteleiro ao desenvolvimento do turismo sustentável em Barra Grande. O frágil estado da sustentabilidade nos meios de hospedagem decorre em alguma medida da falta de infraestrutura básica na localidade, mas, a despeito desta realidade, os principais fatores determinantes têm origem na inexistência de iniciativas e instrumentos de gestão voltados à redução dos impactos gerados e, também, no negligenciamento da responsabilidade social e ambiental dos empreendimentos para com o seu entorno. 
$\mathrm{Na}$ dimensão ambiental é necessário introduzir algumas medidas e intensificar as já existentes de modo a garantir um mínimo de razoabilidade na gestão hoteleira em conformidade com os princípios da sustentabilidade, a exemplo de ações para redução de resíduos, redução do consumo e reuso da água, educação ambiental para funcionários e ações para redução do consumo de energia elétrica.

A dimensão sociocultural mostrou um distanciamento do que se espera de um empreendimentoquantoaoseu compromissosocioambientalcomacomunidade onde está inserido, em que fatores essenciais ao desenvolvimento sustentável do turismo têm pouca importância, tais como: promoção da capacitação em turismo aos funcionários, parcerias com produtores locais, envolvimento com projetos sociais na comunidade e facilidades para mobilidade.

No aspecto econômico da sustentabilidade, um dos fatores que mais comprometem a viabilidade dos negócios é a alta taxa de sazonalidade, o que dificulta o planejamento e a garantia do fluxo de benefícios para a comunidade ao longo do ano. Este sem dúvida é o maior desafio para a Vila de Barra Grande e, da mesma forma, para pequenas comunidades costeiras que sobrevivem do turismo de sol e praia.

Alguns dos resultados obtidos e até mesmo o índice proposto poderão vir a ser tomados como instrumentos de apoio ao planejamento da atividade turística em Barra Grande. Tanto o poder público quanto os empresários locais terão em mãos dados para o monitoramento e a identificação dos pontos que requerem maior atenção e com oportunidades de melhoria. O Índice de Sustentabilidade Hoteleira poderá ter sua metodologia replicada e testada em outros destinos, adaptada às especificidades de cada lugar e à estrutura hoteleira.

Assim, é importante reconhecer que, embora o destino Barra Grande tenha nos seus atrativos naturais seu mais importante atrativo turístico e determinante para os visitantes quando da sua decisão de viajar, os resultados mostram um contexto de fragilidade nas dimensões da sustentabilidade por parte do setor hoteleiro que pode comprometer a qualidade da visitação e indica também um quadro de condições ambientais, sociais e econômicas ainda insatisfatórias para contribuir com o turismo sustentável no destino em análise. Sabe-se que 
o destino carece de uma infraestrutura adequada para garantir um mínimo necessário às residências e aos empreendimentos, especialmente em termos de abastecimento de água e saneamento básico, o que se deve ter em conta em uma investigação mais detalhada em pesquisas futuras.

\section{REFERÊNCIAS}

ASSUNÇÃO, R.; AMORIM, T.; MONDO, T. S. Sustentabilidade em Meios de Hospedagem: Estudo de Caso em Meio de Hospedagem de Garopaba. $2^{\circ}$ Simpósio de Integração Científica e Tecnológica do Sul Catarinense - SICT-Su, p. 278-289, 2013.

BARDDAL, R.; ALBERTON, Anete; CAMPOS, Lucila M S. As dimensões e métodos de mensuração da sustentabilidade e o Turismo: uma discussão teórica. Revista de gestão social e ambiental. mai/ago. 2010, v.4,n.2, p.138-55.

BUCKLEY, R. Sustainable tourism: Research and reality. Annals of Tourism Research, 2012.

BUTLER, J. The compelling "hard case" for "green" hotel development. Cornell Hospitality Quarterly, vol. 49, issue 3 p. 234-244, 2008.

COOPER, C.; FLETCHER, J.; WANHILL, S.; GILBERT, D. \& SHEPHERD, R. Turismo, princípios e práticas. 2 ed. Porto Alegre: Bookman, 2001.

CORDEIRO, I.; BENTO, E.; BRITTO, C. Turismo e desenvolvimento sustentável: considerações sobre o modelo de resorts no litoral nordeste do Brasil. Caderno Virtual de Turismo. Rio de Janeiro, v. 11, n. 3, p.355-369, dez. 2011.

CUNHA, S. K. \& CUNHA, J. C.. Competitividade e sustentabilidade de um cluster de turismo: uma proposta de modelo sistêmico de medida de impacto do Turismo no desenvolvimento local. Revista de Administração Contemporânea, 9(2), 110-124. 2005.

DIAS, Reinaldo. Turismo Sustentável e Meio Ambiente. São Paulo: Atlas, 2003.

ENZ, C. A.; SIGUAW, J. A. Best hotel environmental practices: Cornell Hotel and Restaurant Administration Quaterly, p. 72-77, Oct 1999.

ESPINHA, Ana Maria Lopez (Org.). Gestão sustentável e qualificação profissional em meios de hospedagem. Conselho Nacional da Reserva da Biosfera da Mata Atlântica. São Paulo, caderno 39, 2010.

GOMES, R. de A. Análise da Sustentabilidade da Atividade de Turismo Rural no Distrito Federal: O Caso dos Hotéis-Fazenda. 2005,171 f. Dissertação (Mestrado) - Faculdade de 
Agronomia e Medicina Veterinária, Universidade de Brasília. Brasília, 2005.

HANAI, Frederico Yuri. Sistema de indicadores de sustentabilidade: uma aplicação ao contexto de desenvolvimento do turismo na região de Bueno Brandão, Estado de Minas Gerais, Brasil. 2009, 432 f. Tese (Doutorado em Engenharia Ambiental) Universidade de São Paulo. São Carlos, 2009.

IRVING, Marta de Azevedo et al. Revisitando significados em sustentabilidade no planejamento turístico. Caderno Virtual de Turismo. Rio de Janeiro, Vol. 5, n. 4, 2005.

KÖRÖSSY, Nathália. Do "turismo predatório" ao "turismo sustentável": uma revisão sobre a origem e a consolidação do discurso da sustentabilidade na atividade turística. Caderno Virtual de Turismo. Rio de Janeiro, Vol. 8, n.2, 2008.

LICKORISH, L. \& JENKINS, C. L. Introdução ao turismo. Rio de Janeiro: Campus, 2000.

MALTA, M.; MARIANI, M. Estudo de caso da sustentabilidade aplicada na gestão dos hotéis de campo grande, MS. Revista Turismo Visão e Ação, v. 15, p. 112-129, 2013. Disponível em: <http://periodicos.bce.unb.br/index.php/sust/article/download/8124/6183>. Acesso em: 1/9/2014.

MELLO, R.; NAIME, R.; HUPFFER, H. M. Avaliação sobre o uso de práticas de sustentabilidade na hotelaria - Estudo de caso em hotéis de uma cidade do litoral norte do RS. Rev. Elet. em Gestão, Educação e Tecnologia Ambiental, v. 8, p. 1689-1699, 2012.

MINISTÉRIO DO TURISMO (MTUR). Programa de Regionalização do Turismo - Roteiros do Brasil: Turismo e Sustentabilidade. Brasília, 2007.

MINISTÉRIO DO TURISMO (MTUR). Dados e fatos. Estatísticas e indicadores do turismo no mundo 2013. Disponível em: <http://www.dadosefatos.turismo.gov.br/export/ sites/ default/dadosefatos/estatisticas_indicadores/downloads_estatisticas/Estatistica_e_ indicadores_Turismo_no_mundo_2013.pdf>. Acesso em: 02 dez. 2014.

MELLO, Rita; NAIME, Roberto; HUPPFER, Haide Maria. Avaliação sobre o uso de práticas de sustentabilidade na hotelaria-estudo de caso em hotéis de uma cidade do litoral norte do RS. Revista Eletrônica em Gestão, Educação e Tecnologia Ambiental, v. 8, n. 8, p. 16891699, 2012.

ORGANIZAÇÃO MUNDIAL DO TURISMO (OMT). Agenda 21 for the travel and tourism industry: towards environmentaly sustainable development. Madri, 1994.

ORGANIZAÇÃO MUNDIAL DO TURISMO (OMT). Indicadores de desarrollo sostenible 
para los destinos turísticos: guía práctica. Madrid: OMT, 2005.

PERES JR., M. R.; REZENDE, D. C. Gestão da sustentabilidade no segmento hoteleiro : estudo dos meios de hospedagem de Monte Verde, MG. Caderno Virtual de Turismo, v. 11, p. 234-252, 2011.

PLATIAU, A. et al. Uma crise anunciada. In: THEODORO, Suzi. Mediação de conflitos socioambientais. Rio de Janeiro: Garamond, 2005.

RUDIO, Franz Victor. Introdução ao projeto de pesquisa científica. Petrópolis: Vozes, 1986.

RUIZ, João Alvaro. Metodologia cientifica: guia para eficiência nos estudos. 6. ed. São Paulo: Atlas, 2006.

RUSCHMANN, D. Turismo e planejamento sustentável: a proteção do meio ambiente. 6 . ed. Campinas: Papirus, 2000.

SACHS, I. Caminhos para o desenvolvimento sustentável. 4. ed. Rio de Janeiro: Garamond, 2002.

SANCHO, A. (org.) Introdução ao turismo. OMT. São Paulo: Roca, 2001.

SECRETARIA DO TURISMO DO ESTADO DA BAHIA. Destinos indutores. Disponível em: <http://www.setur.ba.gov.br/zonas-turisticas/destinos-indutores/>. Acesso em: 15 mar. 2012.

SWARBROOKE, J. Turismo sustentável: meio ambiente e economia. Vol. 2 - tradução: Esther Eva Horovitz. São Paulo: Aleph, 2000. 136 p.

VALENTE, Priscila Souza. Meio de hospedagem e desenvolvimento sustentável. 2007, 68 f. Monografia (Especialização em Gestão de Negócios em Turismo) Universidade de Brasília. Brasília, 2007.

VIEIRA, José Guilherme Silva. Metodologia de pesquisa científica na prática. Curitiba: Editora Fael, 2010.

VIRGINIO, D.; FERNANDES, L. Responsabilidade socioambiental na hotelaria : um estudo na via costeira de Natal, RN. Caderno Virtual de Turismo, v. 11, p. 220-233, 2011. 